\title{
Pictorial instrument to guide the classification of foods in the dietary Guidelines for the Brazilian Population
}

\author{
Instrumento iconográfico para orientação \\ da classificação de alimentos do Guia
} Alimentar para a População Brasileira

Marina Vilar GERALDI ${ }^{1}$

Isabella Queiroz LEITE ${ }^{1}$

Stephanie Nayara PINTO'

Rosa Wanda DIEZ-GARCIA²

\section{A B S T R A C T}

This communication describes an instrument for food and nutrition education of food categories based on the new classification according to type of commercial processing, used by the Dietary Guidelines for the Brazilian Population published by the Ministry of Health. The instrument uses, in a practical and schematic manner, the visual resources of food "circles", colors and images. This scheme aims to guide the most appropriate and healthy proportions, as follows: the largest circle contains the foods that should be consumed in the greatest amounts, and so on, until the smallest circle. The front of the circles presents images of foods of each food category, and the back contains a brief explanation about what the foods are and the recommended intake for each category. The instrument aims to mediate and facilitate the guidance of this classification by using a pictorial resource, helping individuals to make food choices autonomously. It is not only aimed at the population, but also at health professionals and educators who seek to promote the population's health. The instrument may be used as a visual aid in individual nutrition care and in groups of food and nutrition education.

Keywords: Food and nutrition education. Food guide. Nutritional counseling.

\section{R E S U M O}

Esta comunicação descreve um instrumento para educação alimentar e nutricional de categorias de alimentos de acordo com a nova classificação baseada no tipo de processamento industrial, usada no Guia Alimentar

\footnotetext{
1 Universidade de São Paulo, Faculdade de Medicina de Ribeirão Preto, Curso de Nutrição e Metabolismo. Ribeirão Preto, SP, Brasil.

2 Universidade de São Paulo, Faculdade de Medicina de Ribeirão Preto, Departamento de Clínica Médica. Ribeirão Preto, SP, Brasil. Av. Bandeirantes, 3900, Monte Alegre, 14049-900, Ribeirão Preto, SP, Brasil. Correspondência para/Correspondence to: RW DIEZ-GARCIA. E-mail: <wanda@fmrp.usp.br>.
} 
para a População Brasileira do Ministério da Saúde. O instrumento foi desenvolvido utilizando-se de forma prática e esquemática os recursos visuais de proporção dos "círculos", cores e imagens de alimentos. Esse esquema é usado para orientar as proporções mais adequadas e saudáveis, de modo que, no círculo maior, constam os alimentos que devem ser consumidos em maior quantidade e, no menor deles, os que devem ser consumidos em menor quantidade. Utilizando-se da face principal de cada círculo, são apresentadas imagens de alimentos os quais representam cada categoria alimentar e, no verso, uma breve explicação sobre o que são e as recomendações de ingestão de cada categoria. O instrumento visa mediar e facilitar a orientação dessa classificação por meio de recurso visual iconográfico, de modo a apoiar indivíduos em escolhas alimentares com autonomia. Dirige-se à população e, também, a profissionais de saúde e educadores que buscam a promoção da saúde na população. O instrumento pode ser utilizado como material de apoio em atendimentos nutricionais individuais e em grupos de educação alimentar e nutricional.

Palavras-chave: Educação alimentar e nutricional. Guias alimentares. Orientação alimentar.

\section{INTRODUCTION}

Instruments to support dietary counseling are useful because they provide resources for the understanding and application of information in eating practices ${ }^{1,2}$. The new Dietary Guidelines for the Brazilian Population introduces new concepts and information that need to be transmitted to the population ${ }^{3}$.

Changes that occurred in the eating pattern, characterized by increased intake of processed foods with high energy density and simple sugar content, and in nutrients' physical and chemical characteristics affect the epidemiological profile, with an expressive increase in the rates of overweight, obesity, and chronic diseases ${ }^{4}$.

Strategies to promote healthy eating have been proposed, and Food and Nutrition Education (FNE) stands out, as it integrates actions of food and nutrition security and health promotion policies. These actions are critical for preventing and controlling current food and nutrition problems, such as chronic diseases and nutritional deficiencies, in addition to valuing healthy eating, the Brazilian food culture, and regional habits, promoting sustainable intake, and reducing food waste ${ }^{5,6}$.

Food and Nutrition Education actions aim to promote strategies to expand the population's empowerment to achieve the human right to adequate food and guarantee food and nutrition security ${ }^{5}$.
The new Dietary Guidelines for the Brazilian Population ${ }^{7}$, developed by the Ministry of Health, proposes general principles and recommendations to guide an appropriate and healthy diet for the Brazilian population, prioritizing fresh foods with less commercial processing. The Guidelines propose four food categories: fresh or minimally processed foods, ingredients used in culinary preparations, processed foods, and ultra-processed foods ${ }^{7}$. Food and nutrition education instruments may help to instruct the population about these categories and encourage the adoption of healthy food practices.

Autonomous food choices depend not only on individuals but also on external conditions of the environment in which they live - cultural, social, political, and economic values - that may have a positive or negative influence on their food pattern ${ }^{8}$.

Dietary changes that involve established patterns may or may not be supported by social norms. If knowledge of healthy eating is reconciled with what is available in daily situations, putting in practice changes for a healthy diet is facilitated as they are gradually and imperceptibly incorporated in daily life. On the other hand, when dietary changes are voluntary and depend on personal effort, they are harder to change because they are not a legitimate social practice ${ }^{8,9}$.

To inform and facilitate the management of food categories on choices, a teaching material was created based on the Dietary Guidelines for 
the Brazilian Population? ${ }^{7}$. It is a visual aid for promoting appropriate and healthy diet in the Brazilian population.

\section{Food classification}

Studies about nutrition and public health were based on nutrients and foods, ignoring the type of commercial processing. Food guides, such as the American food pyramid, encourage the intake of healthier foods, which means foods rich in what are considered desirable nutrients ${ }^{10}$. Thus, foods with different nutritional compositions and impacts on health were classified as belonging to the same food group, such as, for example, fresh fruits, fruit preserves, and reconstituted fruit juices with added sugar.

Today it is recognized that many changes in eating patterns, the current cooking decline, and the increase in fast food intake have been associated with obesity and diet-related chronic diseases ${ }^{4,11}$. Transferring food preparation to large companies resulted in lower costs and more free time for other activities, presumable benefits that only now begin to be assessed. Companies use much more sugar, fat, and salt than home cooks, and they also use chemical ingredients to increase shelf life ${ }^{10}$. Population studies on the Brazilian diet show that the proportion of ultra-processed foods consumed in Brazil increased. In 2009 it corresponded to $28 \%$ of the total calories ${ }^{12}$; in 2003 , to $23 \%$; and in the 1980 s, to less than $20 \%{ }^{13}$.

At first, foods were classified into two categories only: not processed and processed ${ }^{14}$. In 2010 Monteiro specified a new classification according to type of commercial processing, which divides foods into three categories: minimally processed foods (Group 1), culinary ingredients (Group 2), and ultra-processed foods (Group 3). Public policies, regulations, and specific laws are needed to deter and revert the current replacement of the foods in Groups 1 and 2 by ultra-processed foods ${ }^{3,10}$.
Based on this scenario, in the 2014 Dietary Guidelines for the Brazilian Population, the Ministry of Health proposes a food classification based on the amount of processing the food underwent, replacing the recommendation of the 2006 edition, which was based on food groups and recommended servings. According to the new publication, foods are classified as: fresh foods and minimally processed foods (a); oils, fats, salt, and sugar (b); processed foods (c); and ultra-processed foods (d). The guide also contains information about the environmental impacts of food choices and advises individuals to have meals in appropriate environments, reinforcing cultural aspects of shared meals ${ }^{7}$.

The instrument presented herein is a pictorial resource organized by colors and sizes to help professionals that mediate food and nutrition education ${ }^{15,16}$ to provide counseling on the food categories in the Dietary Guidelines for the Brazilian Population. It aims to facilitate the understanding of food categories, a condition that may provide greater food choice autonomy ${ }^{17}$ (Chart 1).

\section{Shape and size}

The instrument uses a scheme of "circles" that takes into account the proportions that should be consumed in each food category. The largest circle contains the foods that should be consumed in the greatest amounts, and so on, until the smallest circle. Therefore, the instrument is a pictorial resource that demonstrates, in a practical and schematic manner, food categories, and suggests the most appropriate and healthy proportions.

The front of each circle contains images that represent each food category, and the back briefly explains the foods and how much should be consumed of each category. The largest circle represents the first category of fresh and minimally processed foods. These should be the basis of the diet and should be as diverse as possible. The second category, oils, fats, salt, and sugar, is 
Chart 1. Instrument to guide the foods choices recommended by the Dietary Guidelines for the Brazilian population.

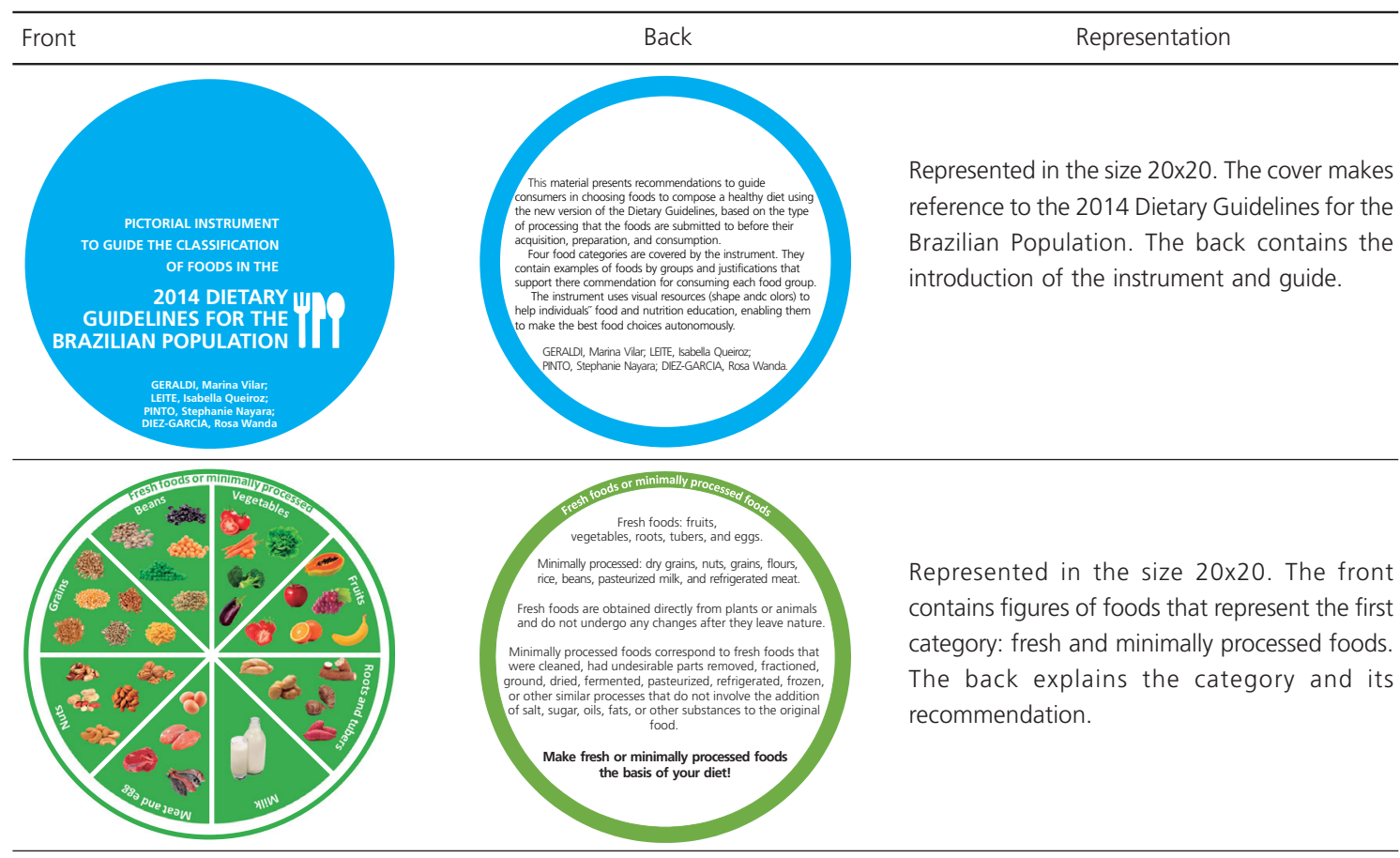
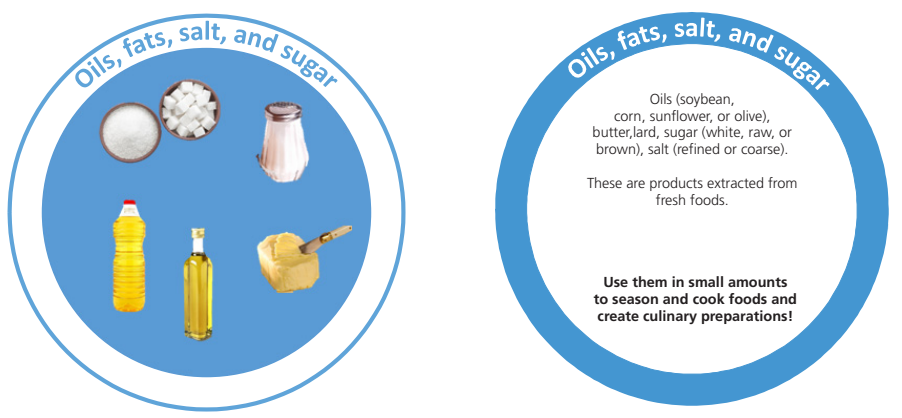

Represented in the size $10 \times 10$. The front contains figures of foods that represent the second category: ingredients used in culinary preparations, oils, fats, salt, and sugar. The back explains the food category and its recommendation.

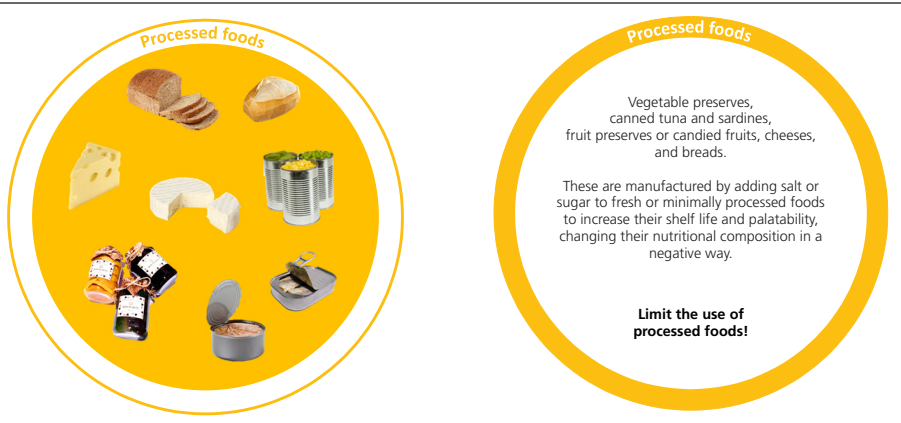

Represented in the size $15 \times 15$. The front contains figures of foods that represent the third category: processed foods. The back explains the food category and its recommendation.
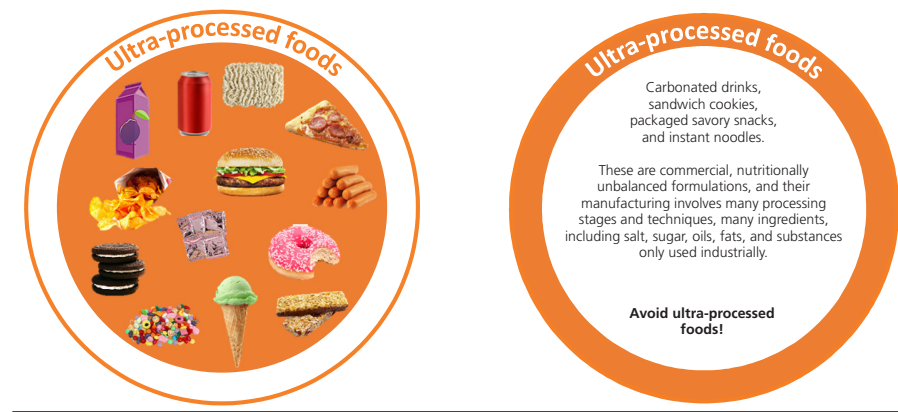

Represented in the size $10 \times 10$. The front contains figures of foods that represent the fourth category: ultra-processed foods. The back explains the food category and its recommendation. 
represented by the small circle. These are foods used for seasoning, cooking, and creating culinary preparations, and they should be used with moderation. The third category, represented by the mid-sized circle, corresponds to processed foods. Their intake should be limited, and they should be used preferably as ingredients or side dishes.

The fourth category of ultra-processed foods should be avoided because the foods therein do not only contain too much sugar and fat, but their nutrients undergo changes during processing that may impact our metabolism. The category is therefore represented by a small circle. Additionally, the way those foods are consumed, and their portability and ease of consumption, among others modify conventional eating practices, which end up being replaced by these undesirable foods.

Excess intake of ultra-processed foods is associated with heart diseases, obesity, and other chronic diseases, and may have negative impacts on the food culture, social life, and environment. This category encourages an intake pattern that dispenses unnecessary food preparation, sitting at the table for meals, and food sharing. Ultraprocessed foods often replace fresh or minimally processed foods, changing regional food practices and facilitating excessive calorie intake. Moreover, there is also the environmental damage caused by the large amount of disposable packaging and by the unsustainable production manner, which involves high demand of raw materials and promotion of monocultures, which threatens the planet's sustainability?

Color is the first factor to strike the observer. Hence, it should match content and concept as its suggestive and persuasive powers take into account emotional aspects and can improve understanding, learning, and reading 18,19.

The language of color has triple action: to impress, it is an attractive medium that acts on consumers' subconsciousness after the initial sight; to express messages about our senses; and to construct a language that communicates an idea. Traffic lights, for example, use colors with easily verifiable connotations: red means alarm, danger; yellow means attention; and green means safety, free passage ${ }^{18}$.

Green is a color associated with health, tranquility, ecology, and nature, stimulating harmony and balance between body and emotions $^{18}$. It was used to identify the category of "fresh or minimally processed foods" to connote vegetables, fruits, tubers, and roots, to encourage their intake.

Blue creates a sense of confidence and security, transmits calmness, reduces appetite, and encourages productivity ${ }^{19}$. The color was used in the category "oils, fats, salt, and sugar", indicating foods whose consumption should be limited.

Yellow, a color less intense than red, is associated with gold and wealth ${ }^{18}$. It was used in the category "processed foods".

Orange is a red softened by yellow, it has the power to get the observer's attention, it indicates danger, such as, for example, poisons, which are identified with a skull on an orange background ${ }^{19}$. This color indicates energy potential, increased muscle tension and blood pressure, and may suggest prohibition and revolution. It interferes on the sympathetic nervous system, which is responsible for the alert, offensive, and defensive states. This color was used for representing the category "ultra-processed foods" with the objective of drawing attention and restricting intake.

As an element of visual code, color has autonomous power of communication. In other words, regardless of where it is used or the shapes that contain it, color by itself communicates and informs. Therefore, it is important in the creative process of visual identity.

\section{CONCLUSION}

The pictorial instrument for food and nutrition education that classifies foods in the 2014 Dietary Guidelines for the Brazilian 
Population uses accessible language and visual resources to mediate and facilitate autonomous food choices. It directly targets the population and also health professionals and educators who seek to promote health.

The construction of this material evoked the challenge of proposing a food and nutrition education instrument that could translate to the population, in a dynamic and accessible manner, the content of the new food categorization presented by the Dietary Guidelines.

The instrument can be used as a visual aid in individual nutrition care and in groups of food and nutrition education. Individuals may manipulate the instrument, interact, and talk about the subject with the dietitian, and based on this familiarization, consumers can be challenged to assess their own food intake according to this classification.

We hope that the instrument can help individuals to access reliable information about appropriate and healthy diets, contributing to increase food choice autonomy. The instrument will undergo other improvement stages, including its assessment and validation in different groups to verify its efficiency and utility in nutritional counseling.

\section{OLABORADORES}

MV GERALDI, IQ LEITE and, SN PINTO participated in the planning and development of the study and article writing. RW DIEZ-GARCIA participated in the planning of the study and article analysis and review.

\section{RE FER E N CES}

1. Diez-Garcia RW, Cervato-Mancuso AM. Ações educativas, programas e políticas envolvidas nas mudanças alimentares. In: Mudanças alimentares e educação nutricional. Rio de Janeiro: Guanabara Koogan; 2011.

2. Santos LAS. O fazer educação alimentar e nutricional: algumas contribuições para reflexão. Ciênc
Saúde Coletiva. 2012;17(2):453-62. https://doi. org/10.1590/S1413-81232012000200 029

3. Monteiro CA, Levy RB, Claro RM, Castro IRR, Cannon G. A new classification of foods based on the extent and purpose of their processing. Cad Saúde Pública. 2010;26(11):2039-49. https:// doi. org/10.1590/S0102-311X2010001100005

4. World Health Organization. Diet, nutrition and the prevention of chronic diseases. Technical Report Series, nº 916. Geneva: WHO; 2003.

5. Brasil. Ministério do Desenvolvimento Social e Combate à Fome. Marco de referência de educação alimentar e nutricional para as políticas públicas. Brasília: Ministério do Desenvolvimento Social e Combate à Fome; 2012.

6. Brasil. Ministério da Saúde. Política Nacional de Alimentação e Nutrição. Brasília: Ministério da Saúde; 2012.

7. Brasil. Ministério da Saúde. Guia alimentar para a população brasileira. Brasília: Ministério da Saúde; 2014 [2015 nov 12]. Disponível em: http://portal saude.saude.gov.br/images/pdf/2014/novembro/ 05/Guia-Alimentar-para-a-pop-brasiliera-MioloPDF-Internet.pdf

8. Diez-Garcia RW. Mudanças Alimentares: implicações práticas, teóricas e metodológicas. In: Diez-Garcia RW, Cervato-Mancuso AM. Mudanças alimentares e educação nutricional. Rio de Janeiro: Guanabara Koogan; 2011.

9. Diez-Garcia RW. A comida, a dieta, o gosto: mudanças na cultura alimentar [doutorado]. São Paulo: Universidade de São Paulo; 1999.

10. Monteiro CA. Nutrition and health: The issue is not food, nor nutrients, so much as processing (Invited commentary). Public Health Nutr. 2009;12(5):729-31. https://doi.org/10.1017/S1368980009005291

11. Pollan M. Cozinhar: uma história natural da transformação. Rio de Janeiro: Intrínseca; 2014.

12. Martins APB, LEVY RB, Cloro RM, Moubarac JC, Monteiro CA. Alimentos ultraprocessados e perfil nutricional da dieta no Brasil. Rev Saúde Pública. 2015; 49(38):1-10. https://doi.org/10.1590/S00 34-8910.2015049006132

13. Martins APB, Levy RB, Claro RM, Moubarac LC, Monteiro CA. Increased contribution of ultraprocessed food products in the Brazilian diet (1987-2009). Rev Saúde Pública. 2013; 47(4):656-65. https://doi.org/10.1590/S0034-8910.20130470 04968

14. Hawkes C. Promoting health diets and tackling obesity and diet-related chronic diseases: What are 
the agricultural policy levers? Food Nutr Bull. 2007;28(2Suppl.):S312-22.

15. Micali FG. Construir e avaliar um instrumento imagético para orientação alimentar [mestrado]. Ribeirão Preto: Universidade de São Paulo; 2013.

16. Houts PS, Doak LG, Loscalzo MJ. The role of pictures improving health communication: A review of research on attention, comprehension, recall, and adherence. Patient Educ Couns. 2006;61(2):173-90. https://doi.org/10.1016/j.pec.2005.05.004

17. Contento IR. Nutrition Education: Linking research, theory and practice. In: foundation in theory and research: Increasing awareness and enhancing motivation. Sudbury: Jones \& Bartlett; 2010.

18. Farina M, Perez C, Bastos D. Psicodinâmica das cores em comunicação. $5^{a}$ ed. São Paulo: Edgard Bucher; 2006.

19. Heller E. A psicologia das cores. São Paulo: GGBrasil; 2014.

Received: February 25, 2016

Final version: August 29, 2016

Approved: September 14, 2016 
